\title{
Sentencia dictada por la Corte Suprema en el Caso Prats
}

Este comentario, junto a los documentos que analiza, está disponible en www.anuariocdh.uchile.cl

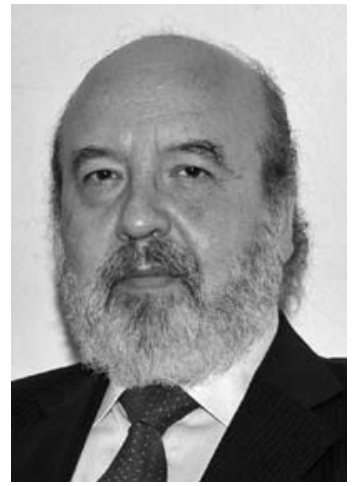

\section{Hernán Quezada Cabrera}

Doctor en Derecho por las Universidades de Hamburgo y de Estrasburgo. Obtuvo el grado de Licenciado en Ciencias Jurídicas y Sociales de la Universidad de Chile y el Diploma de Especialización en Relaciones Internacionales de la Pontificia Universidad Católica de Chile. Fue abogado de la Vicaría de la Solidaridad, Jefe del Área de Derecho Internacional Público en la Dirección de Asuntos Jurídicos del Ministerio de Relaciones Exteriores, Consejero Legal de la Misión Permanente de Chile ante las Naciones Unidas en Nueva York y Coordinador de Estudios de la Academia Diplomática de Chile "Andrés Bello". Ha sido abogado querellante en numerosas causas judiciales por violaciones a los derechos humanos, incluido el caso Prats. Actualmente es abogado de la Dirección de Asuntos Jurídicos de la Cancillería y Profesor de Derecho Internacional en la Universidad Academia de Humanismo Cristiano.

hquezada@hotmail.com

\section{RESUMEN}

El artículo analiza la sentencia de la Corte Suprema de 8 de julio de 2010 que puso término al "Caso Prats". En el contexto de la jurisprudencia en materia de violaciones a los derechos humanos, el autor destaca algunos avances significativos, como la aplicación de la figura penal de la "asociación ilícita" a los miembros de la DINA que participaron en los asesinatos, y critica otros, como el reconocimiento de la "media prescripción" para graduar la penalidad de delitos considerados imprescriptibles. Aunque se cuestiona el empleo de la media prescripción respecto de crímenes contra la humanidad, se reconoce que la Corte hizo una aplicación diferenciada de la misma, valiéndose para ello de la potestad discrecional del juez para atenuar las penas correspondientes.

El 8 de julio de 2010, la Corte Suprema pronunció la sentencia que puso término al denominado "Caso Prats", condenando a nueve individuos por su responsabilidad en los delitos investigados. Este fallo, recaído en uno de los crímenes más atroces del período dictatorial, constituyó la culminación de un proceso judicial iniciado en Argentina el 30 de septiembre de 1974, fecha en la que el General Carlos Prats y su cónyuge Sofía Cuthbert perecieron en la ciudad de Buenos Aires como consecuencia de un acto terrorista planificado en la Dirección de Inteligencia Nacional (DINA) ${ }^{1}$.

1 Como resultado de una solicitud de extradición por parte de la justicia argentina de varios ex miembros de la DINA y de Augusto Pinochet Ugarte, la Corte Suprema ordenó abrir con fecha 2 de diciembre de 2002 un proceso en nuestro país por los delitos de asociación ilícita y homicidios calificados del General Carlos Prats y su señora Sofía Cuthbert, en contra de Juan Manuel Contreras Sepúlveda, Pedro Espinoza Bravo, Raúl Eduardo Iturriaga Neumann, José Zara Holger y Jorge Iturriaga Neumann. La Corte Suprema, si bien estimó que se cumplían los requisitos para la extradición de estos cinco requeridos, decidió hacer uso de una facultad conferida a los Estados Partes por el Tratado de Montevideo sobre Extradición, de 1933, de no entregar a sus nacionales al país requirente, pero quedando obligados a juzgarlos por sus 
La Corte Suprema, con motivo de los recursos de casación deducidos por las defensas de los condenados, decidió invalidar de oficio la sentencia de la Corte de Apelaciones de Santiago, de fecha 29 de enero de 2009, confirmatoria del fallo de primera instancia dictado algunos meses antes por el Ministro de Fuero Alejandro Solís, quien había impuesto altas penas a los responsables de los delitos cometidos, esto es, homicidios calificados y asociación ilícita.

En el marco de la jurisprudencia nacional en materia de violaciones a los derechos humanos ${ }^{2}$, la sentencia del máximo tribunal exhibe algunos avances significativos, pero también contiene elementos cuestionables. Entre los primeros, debe mencionarse la aplicación del tipo penal de la "asociación ilícita" a miembros de la DINA que participaron en los asesinatos. Entre los segundos, el empleo de la "media prescripción" para atenuar la penalidad de delitos considerados imprescriptibles, aun cuando se excluyó de este beneficio a quienes fueron condenados en calidad de autores del doble homicidio.

\section{La asociación ilícita que planificó y ejecutó los homicidios}

La sentencia de primera instancia había dado por establecido que la DINA "se constituyó en asociación ilícita con el objeto de atentar contra aquellas personas residentes en Argentina y otros países que eran consideradas 'enemigas' o un peligro para el Gobierno Militar de Chile, formando para tal fin la estructura denominada 'Departamento Exterior'"'3. Aunque invalidado, no es irrelevante recordar que el fallo de segunda instancia, dictado en esta causa por la Corte de Apelaciones de Santiago, calificó explícitamente a esta asociación ilícita, perteneciente a la DINA y creada para actuar en el extranjero, como una organización de "carácter terrorista, caracterizada por la aceptación y empleo de la violencia extrema como recurso para combatir a los opositores políticos" ${ }^{4}$.

La Corte Suprema analizó esta figura penal en ocho extensos Considerandos, concluyendo que en la causa Prats "más allá de la discusión doctrinaria, resulta indubitable que la asociación ilícita concibió, diseñó y aplicó un plan a desarrollar de acuerdo a requisitos o estándares como son los de una organización criminal, lesionando intereses vitales, individuales y colectivos, que todo legislador ha querido proteger jurídicamente, dada su alta significación social" ${ }^{5}$. De interés resulta destacar que, en esta parte del fallo, la Corte Suprema reiteró los razonamientos contenidos en su sentencia del 2 de diciembre de 2002, pronunciada en el proceso de extradición que se instruyera a requerimiento de la justicia argentina en relación a estos hechos:

"Que de los mismos antecedentes [los aportados por el Tribunal de la República Argentina]... se debe coincidir con la conclusión que dicha resolución expresa en cuanto esos homicidios no

propios tribunales (dicha resolución no incluyó a Augusto Pinochet Ugarte puesto que una solicitud de desafuero a su respecto, tramitada en el intertanto, había sido rechazada debido a que este imputado se encontraba sobreseído definitivamente por demencia incurable en el caso "Caravana de la Muerte"). Cfr. Corte Suprema, rol 2908/2002, autos sobre Apelación en Extradición Pasiva, c/Augusto Pinochet Ugarte y otros.

2 Un desarrollo de la jurisprudencia de la Corte Suprema en materia de violaciones a los derechos humanos puede encontrarse en: GUZMÁN D'Albora, José Luis. El tratamiento de los crímenes internacionales en la jurisprudencia chilena: una cabeza de Jano. Lateinamerika Analysen. Institut für Lateinamerika-Studien, Hamburg, año 18 (3): 95 122; 2007. Para una síntesis más reciente sobre la jurisprudencia del máximo tribunal chileno en esta materia, véase: FERNÁNDEZ, Karinna. La prescripción gradual, aplicada a los delitos de lesa humanidad. Tesis (Magíster en Derecho). Santiago, Chile. Universidad de Chile. Facultad de Derecho, 2010. 203 p.

3 Corte de Apelaciones de Santiago, Ministro de Fuero Alejandro Solís, causa rol 2.182-98, Considerando $74^{\circ}$.

4 Corte de Apelaciones de Santiago, autos sobre Recurso de Apelación, rol 3.123-08, Considerando $6^{\circ}$.

5 Corte Suprema, autos sobre Recurso de Casación, rol 2.596-09, sentencia de reemplazo, Considerando Duodécimo, párrafo final. 
pudieron ser el fruto de la acción de una sola persona, sino que éstos se configuraron en el marco del accionar de una asociación criminal debidamente conformada en lo material y dentro de una jerarquía de funciones para el logro del propósito antijurídico de eliminar a una persona de manera segura y premeditada"(Considerando Vigésimo sexto).

"[...] [R]esulta demostrado para estos fines procesales que en la República Argentina operaron miembros de una asociación ilícita que formaron parte de la Dirección de Inteligencia Nacional (D.I.N.A) creada formalmente en el mes de junio de 1.974, que ya había operado de hecho desde fines de 1.973, cuya autoridad máxima era su director Juan Manuel Contreras Sepúlveda, la cual poseía una amplia estructura operativa de carácter clandestina, con una cadena de mando jerarquizada, pero compartimentada en sus operaciones, organización que de manera ilegítima planeó la eliminación física del General Prats porque resultaba peligroso según su visión para la permanencia del Gobierno Militar en Chile"(Considerando Vigésimo séptimo) ${ }^{6}$.

Aunque la Corte Suprema, al igual que el Ministro de Fuero y el tribunal de alzada, no calificó explícitamente a la DINA en su conjunto como asociación ilícita, sino que más precisamente lo hizo respecto de la unidad ("Departamento Exterior") que llevó a cabo los asesinatos del General Prats y su cónyuge, el razonamiento contenido en las sentencias dictadas en esta causa así como los antecedentes fácticos relativos a las operaciones Ilevadas a cabo por la DINA dentro y fuera de Chile habilitan para hacer uso de esta calificación en muchos otros casos en que participaron miembros de esa organización perpetrando crímenes que la propia Corte Suprema, en reiterada y uniforme jurisprudencia, ha tipificado como de lesa humanidad.

De tal manera, la sentencia del tribunal supremo recaída en el caso Prats ha sentado las bases para incriminar en otros procesos judiciales a miembros de la DINA y de otros organismos represivos de la dictadura por su eventual responsabilidad en el delito de asociación ilícita concurrente con los secuestros, homicidios, torturas y demás crímenes en que los mismos tuvieron participación.

\section{Reafirmación de la inamnistiabilidad e imprescriptibilidad de los crímenes de lesa humanidad}

En esta parte, el fallo de la Corte Suprema reafirma su reiterada jurisprudencia iniciada en 1998 con la causa "Poblete Córdova"7 y mantenida -con pocas excepciones- hasta el día de hoy, en el sentido de que respecto de determinados crímenes -como los que se cometieron durante la dictadura de Augusto Pinochet en contra de opositores al régimen- no procede ni la amnistía ni la prescripción, dos causales de extinción de la responsabilidad criminal previstas en nuestro Código Penal.

Aunque la argumentación de la Corte Suprema en este punto es somera, el máximo tribunal ha reafirmado principios fundamentales en la materia y confirmado la aplicabilidad de los Convenios de Ginebra de 1949 y de las normas pertinentes del derecho internacional, para concluir que crímenes como los juzgados en esta causa son inamnistiables e imprescriptibles. Hubiera sido deseable que, en esta materia, los sentenciadores no se limitaran sólo al derecho internacional convencional, sino que también fundaran sus razonamientos en el derecho internacional consuetudinario, fuente fundamental en materia de imprescriptibilidad de los crímenes contra la humanidad.

6 Corte Suprema, rol 2908/2002, autos sobre Apelación en Extradición Pasiva, c/Augusto Pinochet Ugarte y otros.

7 Corte Suprema, autos sobre Recurso de Casación, rol 469-98. 
Igualmente es notoria la ausencia de razonamientos para fundar, en particular, la imprescriptibilidad del delito de asociación ilícita, aun cuando del contexto de la propia sentencia es posible inferir que, en el presente caso, dicha figura penal presenta indiscutiblemente los caracteres de un delito de lesa humanidad y, en consecuencia, resulta imprescriptible. No se trata en este caso de una asociación ilícita común sino de una organización criminal constituida para cometer precisamente crímenes contra la humanidad, como lo fueron sin lugar a dudas los homicidios calificados del General Prats y su cónyuge ${ }^{8}$. En tal sentido, podría sostenerse que la constitución de una entidad como la que perpetró tales asesinatos constituyó un acto preparatorio de estos últimos que debe ser considerado punible atendido el estado actual del derecho internacional en la materia. En efecto, la acción de integrar una asociación o formar parte de un acuerdo de personas para cometer delitos de lesa humanidad es una conducta equiparable, y de igual gravedad, a la de ejecutar tales crímenes, tal como se desprende, entre otros instrumentos, de la Convención para la Prevención y el Castigo del Delito de Genocidio. El artículo III letra b de dicha Convención dispone que será castigada la asociación para cometer genocidio. Por su parte, la Convención contra la Tortura y otros Tratos o Penas Crueles, Inhumanos o Degradantes, establece en su artículo 4 que todo Estado parte velará por que todos los actos de tortura constituyan delitos conforme a su legislación penal, lo cual se aplicará igualmente a toda tentativa de cometer tortura y a todo acto de cualquier persona que constituya complicidad o participación en la tortura (pár. 1).

\section{Indebido e incoherente reconocimiento de la "media prescripción"}

La positiva jurisprudencia emanada de la Corte Suprema en materia de crímenes contra la humanidad a partir del caso "Poblete Córdova" ha experimentado, a nuestro juicio, retrocesos con la introducción artificial y forzada de la denominada "media prescripción" o "prescripción gradual" regulada en el artículo 103 del Código Penal. El propósito de su reconocimiento ha sido reducir significativamente las penas aplicables a los responsables de delitos de tal naturaleza, permitiéndoles de esta manera hacerse acreedores de beneficios tales como la "libertad vigilada" o la "remisión condicional de la pena" que, en la práctica, implican impunidad.

Expresado de manera breve, tanto la prescripción como la media prescripción parten del supuesto del transcurso del tiempo y comparten la misma naturaleza, los mismos fundamentos y ubicación sistemática en el Código Penal. La única diferencia entre ambas consiste en los efectos jurídicos de cada una: la prescripción extingue la responsabilidad penal, mientras que la media prescripción confiere al juez un poder discrecional y facultativo para atenuar la pena aplicable ${ }^{9}$. En este sentido, la media prescripción es una institución jurídica dependiente de la prescripción o, expresado en otras palabras, "las normas que contemplan la prescripción gradual no son sino un reflejo de las normas reguladoras de la prescripción"10.

Tal como lo ha venido sosteniendo desde el año $2007^{11}$, la Corte Suprema manifestó en este nuevo fallo que "la imposibilidad de aplicar la institución de la prescripción de la acción penal, que es causal extintiva de la responsabilidad, en los delitos de lesa humanidad, no alcanza sin más a la media prescripción, prescripción gradual, parcial o incompleta, como también se la denomina, cuyo efecto es una mera disminución de la cuantía de la pena". Y agrega que a esta última "no son

8 Algunos razonamientos en este mismo sentido pueden encontrarse en la sentencia de primera instancia dictada por el Ministro de Fuero Alejandro Solís. Cfr. causa rol 2.188-98, Considerando $77^{\circ}$.

9 Cfr. FERNÁNDEZ, K. y SFERRAZZA, P. La aplicación de la prescripción gradual del delito en las causas sobre violaciones a los derechos humanos. Anuario de Derechos Humanos 2009 (5) Centro de Derechos Humanos. Facultad de Derecho, Universidad de Chile. pp. 183-192.

10 Ibíd., p. 187.

11 Cfr. FERNÁNDEZ, Karinna. La prescripción gradual, aplicada a los delitos de lesa humanidad. Op. cit., pp. 68 y ss. 
aplicables los principios y fundamentos que determinan la imprescriptibilidad de la acción persecutoria de los delitos de lesa humanidad, con lo que se evita su total impunidad [...]". Siguiendo el razonamiento de la Corte Suprema, podría entonces sostenerse que la media prescripción puede constituir, a contrario sensu, una forma de impunidad parcial de los crímenes contra la humanidad, lo que evidentemente atenta -entre otras consecuencias- contra la "proporcionalidad" y la "pertinencia" de la pena aplicable a violaciones graves a los derechos fundamentales, tal como se desprende de significativos fallos de la Corte Interamericana de Derechos Humanos ${ }^{12}$.

No obstante que, a nuestro parecer, es improcedente el reconocimiento de la denominada media prescripción para los responsables de crímenes contra la humanidad, tal como lo sostuvo el voto de minoría en este punto del fallo, debe reconocerse que la Corte Suprema en el Caso Prats hizo una aplicación diferenciada de la misma, valiéndose para ello de la potestad discrecional que en este sentido posee el juez para atenuar las penas correspondientes.

La Corte no utilizó tal facultad respecto de los autores de los delitos de homicidio del General Prats y su cónyuge, teniendo en consideración para ello la motivación de los culpables, su contribución directa a la materialización segura y sin riesgo del plan criminal acordado, las circunstancias especialmente repudiables de perpetración de los crímenes, las estrechas relaciones jerárquicas que ligaban a la mayoría de los hechores con quien fuera su Comandante en Jefe, la magnitud del daño causado y la necesaria proporcionalidad de las penas con el gravísimo resultado de estos ilícitos. En cambio, la Corte Suprema sí hizo uso de la mencionada facultad tratándose de los cómplices de tales homicidios y de todos quienes fueron, además, condenados por su participación en el delito de asociación ilícita. Como resultado de la decisión del máximo tribunal, del total de nueve condenados, dos no cumplirán sus condenas en un recinto penitenciario, sino que permanecerán sometidos al régimen de libertad vigilada, sumándose a ellos un tercero que ya había sido beneficiado en primera instancia con la remisión condicional de la pena.

\section{Desconocimiento del ejercicio de la acción penal en la República Argentina, por los mismos delitos}

Según el artículo 103 del Código Penal, la prescripción gradual opera cuando el responsable de un delito se presenta o es habido antes de completar el tiempo de la prescripción de la acción penal, pero habiendo ya transcurrido la mitad del necesario para tal efecto, en cuyo caso el tribunal deberá considerar el hecho como revestido de dos o más circunstancias atenuantes muy calificadas y de ninguna agravante.

Para reconocer esta media prescripción, la Corte Suprema -además de hacerla procedente de manera forzada en los delitos de lesa humanidad-desconoció los más de 28 años de persecución penal Ilevados a cabo en la República Argentina por los mismos hechos delictivos, señalando:

"[...] cabe consignar que el procedimiento tendiente a la investigación de los ilícitos indagados comenzó en nuestro país el siete de enero de dos mil tres [...] habiéndose perpetrado el delito de asociación ilícita durante 1974 y los homicidios el día treinta de septiembre de ese mismo año".

"Conforme a los períodos antes referidos [...] para el recuento del término requerido y configurar así la morigerante de responsabilidad penal en estudio, ha de considerarse que transcurrieron más de veintiocho años entre la fecha de comisión de los delitos y el ejercicio de la acción penal en

12 Respecto de la proporcionalidad de la pena, cfr. Corte IDH, caso de la Masacre de la Rochela, Fondo, Sentencia de 11.05.2007, Serie C N ${ }^{\circ}$ 163, pár. 196. En relación a la pertinencia de la pena, cfr. Corte IDH, caso Velásquez Rodríguez, Fondo, Sentencia de 29.07.1988, Serie C No 4, pár. 174; caso Godínez Cruz, Fondo, Sentencia de 20.01.1989, Serie C № 5, pár. 184, y caso La Cantuta, Fondo, Sentencia de 29.11.2006, Serie C № 162, pár. 224. 
nuestro país, cumpliéndose de este modo, la hipótesis temporal a que alude el artículo 103 del Código Punitivo"13, esto es, haber transcurrido al menos la mitad del tiempo necesario para la prescripción de la acción penal.

Este razonamiento, fundado en una situación de hecho, es tanto o más forzado que los otros utilizados para avalar la aplicación de la media prescripción. Los sentenciadores olvidaron por completo que la apertura de un proceso en Chile en el Caso Prats fue el resultado de una decisión de la propia Corte Suprema el año 2002, al declarar procedente la extradición de Manuel Contreras y otros imputados solicitada por la República Argentina ${ }^{14}$, en cuyo territorio operó la asociación ilícita y se cometieron los homicidios calificados, y hacer uso de la facultad concedida al Estado requerido por la Convención de Extradición de Montevideo de 1933 de no entregar a sus nacionales al Estado requirente, pero quedando el mismo obligado a juzgar al individuo reclamado por los hechos que se le hubieren imputado.

La acción penal (indivisible por definición) que ejercieron los tribunales chilenos para perseguir las responsabilidades por delitos cometidos en territorio argentino es, en esencia, una prolongación de aquella en cuya virtud se solicitó la extradición de los principales imputados por estos hechos. En los más de 28 años previos al inicio de la investigación en Chile, el proceso judicial se mantuvo abierto en un tribunal federal de Buenos Aires en forma casi inalterable. En consecuencia, jamás podría sostenerse que transcurrió la mitad o más del tiempo necesario para la prescripción de la correspondiente acción penal por un supuesto no ejercicio de la misma. Lo resuelto en esta ocasión por la Corte Suprema contradice lo expuesto por el mismo tribunal en su sentencia de dos de diciembre de 2002, al pronunciarse sobre las extradiciones solicitadas por la República Argentina.

Más aún, en el fallo recién mencionado la Corte Suprema no sólo tuvo en consideración el carácter imprescriptible de los delitos materia del proceso de extradición atendida su naturaleza, sino que también realizó un examen en el marco de las normas penales comunes que rigen la prescripción, arribando al mismo resultado, esto es, que tales crímenes no estaban prescritos:

"[...] Sin perjuicio de lo anterior el artículo 67 del Código Penal argentino previene que la prescripción se interrumpe por la comisión de otro ilícito o por la secuela del juicio. En esta última parte, nuestro código punitivo, en el artículo 96 establece que la prescripción de la acción penal se interrumpe, perdiéndose el tiempo transcurrido, siempre que el delincuente cometa nuevamente crimen o simple delito, y se suspende desde que el procedimiento se dirige contra él. En el proceso rol B-1.516-93 se ha producido la situación de interrupción o suspensión que impropiamente utiliza nuestro código, ya que en su desarrollo se advierte que el 20 de noviembre de 1.975 se produjo el sobreseimiento provisional de la causa, pero con fecha 16 de noviembre de 1.978 se dispuso la reapertura del sumario, precisamente con motivo de la detención de Townley con ocasión del homicidio de Orlando Letelier ocurrido en Washington, imputado que involucró en el atentado de Prats y su señora a Manuel Contreras y otros agentes de la D.I.N.A., en el cual había tenido abierta participación el mismo Townley, bajo el nombre supuesto de Kenneth Enyart, de este modo, la investigación se dirigió en contra de estos nuevos involucrados, afectando también a Enrique Arancibia Clavel, agente de la D.I.N.A. en Argentina, el que actualmente se encuentra condenado por estos hechos. En la tramitación posterior, se observa según los $N^{\circ} 29$ y 30 del procesamiento una

13 Corte Suprema, autos sobre Recurso de Casación, rol 2.596-09, sentencia de reemplazo, Considerando Vigésimo Segundo.

14 Se trata de la misma solicitud de extradición a que se refiere la Nota 1 supra que incluía, entre los inculpados, a Augusto Pinochet. Cfr. Corte Suprema, rol 2908/2002, autos sobre Apelación en Extradición Pasiva, c/Augusto Pinochet Ugarte y otros. 
interrupción del procedimiento entre el 25 de octubre de 1.990 y el 31 de enero de 1.992, debido a la rebeldía de Arancibia Clavel, plazo insuficiente para hacer operar la prescripción alegada. En estas condiciones no es posible resolver favorablemente en este procedimiento de extradición la prescripción de la acción penal impetrada"15.

De tal manera, la Corte ha utilizado claramente un doble estándar. Para resolver la solicitud de extradición formulada por la justicia argentina constató el 2 de diciembre de 2002 que la prescripción respecto de los delitos materia del requerimiento se había interrumpido o suspendido de acuerdo con las normas comunes atendida la existencia de un proceso en tramitación durante el tiempo previo y, por lo tanto, la acción penal se encontraba vigente a esa fecha. No obstante, al reconocer la media prescripción en su sentencia de 8 de julio de 2010 lo hizo sobre la base de que habrían transcurrido "más de veintiocho años entre la fecha de comisión de los delitos y el ejercicio de la acción penal en nuestro país", ignorando así que durante todo ese tiempo la acción penal se ejerció en la República Argentina y que, a pesar de la paralización del procedimiento en dos oportunidades, no llegó a configurarse el presupuesto temporal a que alude el artículo 103 de nuestro Código Punitivo.

Por último, la Corte Suprema olvida que ella misma había impedido que se investigaran por un tribunal chileno los homicidios de que fueron víctimas el General Carlos Prats y su cónyuge Sofía Cuthbert en Buenos Aires al rechazar, con fecha 20 de octubre de 1993, una petición de la Cámara de Diputados en orden a designar a uno de sus Ministros para tal objeto ${ }^{16}$. A juicio de los trece miembros que integraron en dicha ocasión el Pleno de la Corte, en este caso no se cumplían los presupuestos contemplados en el artículo $52 \mathrm{~N}^{\circ} 2^{\circ}$ del Código Orgánico de Tribunales para acceder al nombramiento solicitado por la Cámara. Recordemos que dicha norma legal había sido introducida en el mencionado cuerpo legal por la Ley $N^{\circ}$ 19.047, de febrero de 1991, una de las denominadas "Leyes Cumplido", y sirvió como fundamento jurídico para designar al Ministro Adolfo Bañados como juez especial en el Caso Letelier ${ }^{17}$.

Aun cuando en el asesinato del General Prats se dieron similares circunstancias a aquellas que rodearon el homicidio del ex Canciller Orlando Letelier, la Corte Suprema estimó en aquella época que el primer caso no ameritaba una investigación judicial en Chile a cargo de un Ministro especialmente designado para tal efecto.

\section{Comentarios finales}

La sentencia de la Corte Suprema pronunciada en el caso Prats contiene elementos dignos de ser destacados en la evolución de la jurisprudencia nacional en causas sobre violaciones graves a los derechos humanos. Particularmente, la aplicación de la figura penal de la "asociación ilícita" a los miembros de la unidad de la DINA que perpetraron los homicidios del General Prats y su cónyuge. Otro tanto cabe señalar respecto de la calificación de estos delitos como "crímenes contra la humanidad" y, por ende, imprescriptibles. Sin embargo, la forzada aplicación de la prescripción gradual o media prescripción en este caso diluyó parte de la trascendencia jurídica del fallo y del correspondiente reproche ético-social a los autores de los delitos, al haberse insistido por parte de la mayoría de los Ministros de la Sala Penal en reconocer una situación que resulta contradictoria con el carácter imprescriptible de delitos de esta naturaleza.

\footnotetext{
15 Corte Suprema, rol 2908/2002, autos sobre Apelación en Extradición Pasiva, c/Augusto Pinochet Ugarte y otros, Considerando Vigésimo Cuarto.

16 Cfr. Corte Suprema, autos Rol VE-0334 (1993).

17 Cfr. QUEZADA, Hernán. Acerca de la Imposible "Justicia Posible": El Caso Prats y la Corte Suprema. Pluma y Pincel. Santiago, Chile (166): 27. 1993.
} 